Picture-story

\title{
Endoscopic cysto-enterostomy in the management of pseudopancreatic cysts
}

Mohan de Silva $^{1}$, R Mahanama ${ }^{2}$ and Dayasiri Fernando ${ }^{3}$

\section{Introduction}

Conventional therapy for symptomatic pseudo-pancreatic cysts has been primarily surgery. More recently endoscopic procedures are being employed with minimal morbidity. We report a patient who underwent such a procedure in our unit with excellent results.

\section{Case report}

A 42-year old alcoholic man was admitted with upper abdominal pain, 6 weeks after an episode of acute pancreatitis. Examination showed a $10 \times 8 \mathrm{~cm}$ epigastric mass. Ultrasonogram confirmed a large pseudopancreatic cyst. Endoscopy with a side-viewing GIF 160 Videoscope showed Grade 2 varices and antral gastritis. The cyst bulged into the first part of duodenum. Pancreaticography showed a non-communicating pseudocyst.

Needle knife was used to bore a hole into the cyst (Figure 1) through which a cannula was introduced and a zebra guide was passed into the cavity. A $10 \mathrm{~F}$ outer sheath cannula was guided over the wire to dilate the passage. A $10 \mathrm{~F}$ double layered polyethylene stent was placed in the cyst cavity over the outer sheath and positioned (Figure 2 ). Free drainage of fluid was observed (Figure 3). The procedure took $20 \mathrm{~min}$ and the patient was discharged in $48 \mathrm{~h}$. When reviewed after two weeks he was asymptomatic. No cyst was palpable on examination.

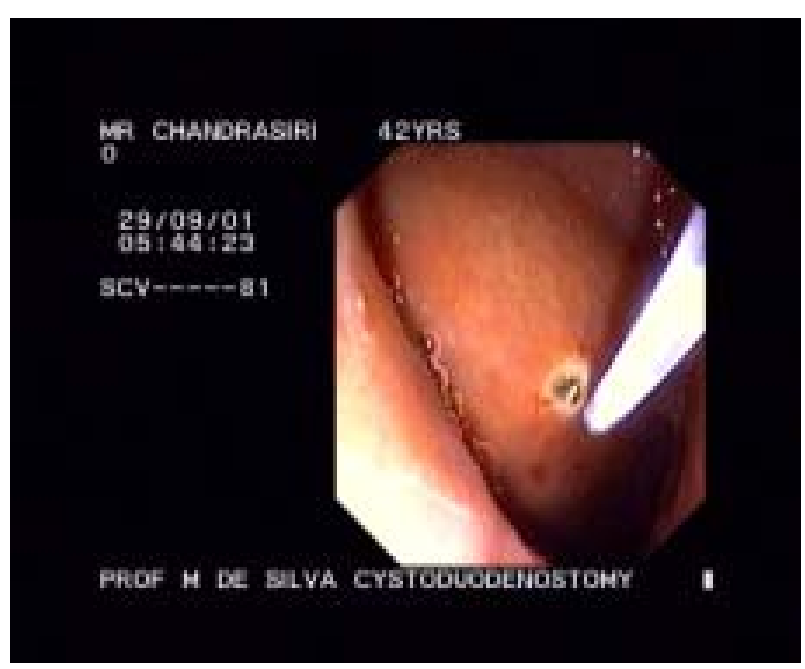

Figure 1.

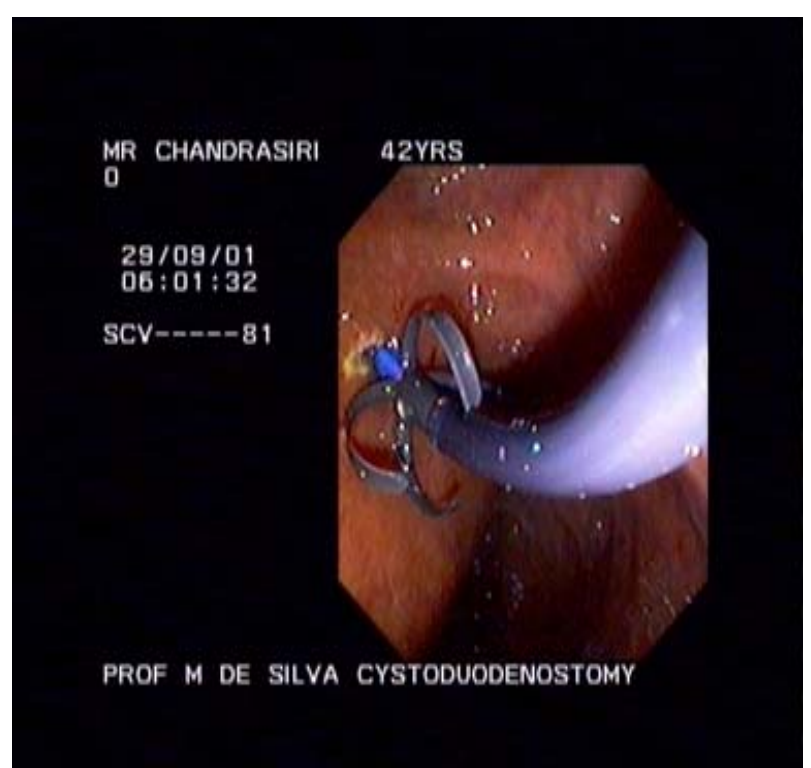

Figure 2.

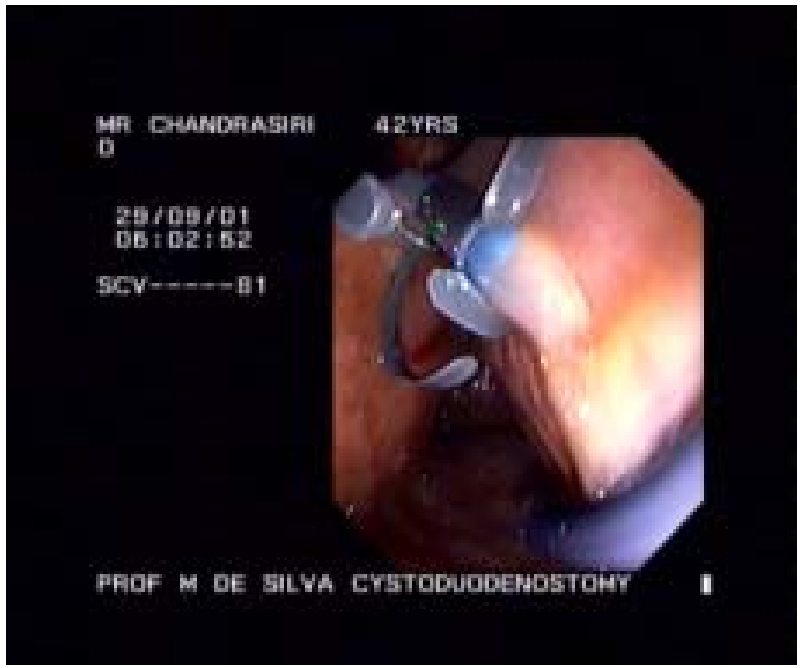

Figure 3.

${ }^{1}$ Professor, ${ }^{2}$ Registrar, ${ }^{3}$ Professor and Head, Department of Surgery, Faculty of Medical Sciences, University of Sri Jayawardenepura, Nugegoda. (Correspondence: $M$ de S, Department of Surgery, University of Sri Jayawardenepura, Nugegoda. Tel: 077 314693, 01 825282. (Submitted 27 October 2001, accepted 2 February 2002). 